\title{
Antimicrobial and Antibiofilm Activities of New Synthesized Silver Ultra-NanoClusters (SUNCs) Against Helicobacter pylori
}

\begin{abstract}
Rossella Grande ${ }^{1,2+}$, Francesca Sisto ${ }^{3 *}$, Valentina Puca 2,4 , Simone Carradori ${ }^{1}$, Maurizio Ronci ${ }^{1,2}$, Antonio Aceto ${ }^{5}$, Raffaella Muraro ${ }^{5}$, Gabriella Mincione ${ }^{5}$ and Luca Scotti ${ }^{5}$
\end{abstract}

${ }^{1}$ Department of Pharmacy, "G. d'Annunzio" University of Chieti-Pescara, Chieti, Italy, ${ }^{2}$ Center for Advanced Studies and Technology (CAST), "G. d'Annunzio" University of Chieti-Pescara, Chieti, Italy, ${ }^{3}$ Department of Biomedical, Surgical and Dental Sciences, University of Milan, Milan, Italy, "Department of Medicine and Aging Science, "G. d'Annunzio" University of Chieti-Pescara, Chieti, Italy, ${ }^{5}$ Department of Medical, Oral, and Biotechnological Sciences, "G. d'Annunzio" University of Chieti-Pescara, Chieti, Italy

Helicobacter pylori colonizes approximately $50 \%$ of the world's population, and it is the cause of chronic gastritis, peptic ulcer disease, and gastric cancer. The increase of antibiotic resistance is one of the biggest challenges of our century due to its constant increase. In order to identify an alternative or adjuvant strategy to the standard antibiotic therapy, the in vitro activity of newly synthesized Silver Ultra-NanoClusters (SUNCs), characterized by an average size inferior to $5 \mathrm{~nm}$, against clinical strains of $H$. pylori, with different antibiotic susceptibilities, was evaluated in this study. MICs and MBCs were determined by the broth microdilution method, whereas the effect of drug combinations was determined by the checkerboard assay. The Minimum Biofilm Eradication Concentration (MBEC) was measured using AlamarBlue (AB) assay and colony-forming unit (CFU) counts. The cytotoxicity was evaluated by performing the MTT assay on the AGS cell line. The inhibitory activity was expressed in terms of bacteriostatic and bactericidal potential, with $\mathrm{MIC}_{50}, \mathrm{MIC}_{90}$, and $\mathrm{MBC}_{50}$ of $0.33 \mathrm{mg} / \mathrm{L}$ against planktonic $H$. pylori strains. Using the fractional inhibitory concentration index (FICl), SUNCs showed potential synergism with metronidazole and clarithromycin. The biofilm eradication was obtained after treatment with $2 \times, 3 \times$, and $4 \times$ MIC values. Moreover, SUNCs showed low toxicity on human cells and were effective in eradicating a mature biofilm produced by $\mathrm{H}$. pylori. The data presented in this study demonstrate that SUNCs could represent a novel strategy for the treatment of $H$. pylori infections either alone or in combination with metronidazole.

Keywords: Helicobacter pylori, drug resistance, silver nanocluster, antibiofilm activity, FIC index

\section{INTRODUCTION}

Helicobacter pylori (H. pylori) colonizes approximately $50 \%$ of the world's population, with a wide variation in the prevalence of the microorganism among regions and countries (Hooi et al., 2017). H. pylori is associated with the development of chronic gastritis and peptic ulcer disease (Eshraghian, 2014), and in 1994, it was classified as type one carcinogen (International Agency 
for Research on Cancer (IARC) 2019). Epidemiological studies indicate that $H$. pylori eradication is associated with a decrease of incidence of gastric cancer (Kosunen et al., 2011) that represents the third most common cancer worldwide with a survival rate longer than 5 years after the diagnosis in 1 over 5 patients affected by this malignancy (Grande et al., 2010; Hooi et al., 2017). The failure of the antibiotic treatment may be due to several factors such as improper regimen, poor patient compliance, internalizing bacteria, gene mutations, transfer of resistance genes, and biofilm formation (Hu et al., 2017). H. pylori has been defined as a "quasi-species" for its wide genetic variability. In fact, it has been demonstrated that $H$. pylori strains isolated from different patients displayed a high degree of variability for the acquisition of new DNA sequences (Taylor et al., 1992; Suerbaum, 2000; Grande et al., 2010). Many studies showed the co-colonization in the same patient of multiple $H$. pylori strains characterized by the resistance or susceptibility to the same antibiotic. Recombination events can occur in the same patient during $H$. pylori infection due to the adaptation of a single strain to stressful stimuli such as sub-inhibitory antibiotic concentrations as well as to mixed infections deriving from the host colonization by different H. pylori strains in time (Grande et al., 2010). In addition, H. pylori can produce a well-structured biofilm characterized by the presence of outer membrane vesicles (OMVs) associated with extracellular DNA (eDNA) (Cole et al., 2004; Cellini et al., 2005; Yonezawa et al., 2009; Grande et al., 2015). It has been demonstrated that the eDNA associated with OMVs facilitates cell-to-cell binding and contributes to the stability of the biofilm matrix. Moreover, the nucleic acid is protected by the vesicle structures guaranteeing both delivery and release of the genetic information and important proteins in other bacterial cells, and H. pylori pathogenesis and survival (Grande et al., 2015; Ronci et al., 2019). In addition, Yonezawa et al. (2011) demonstrated the key role of a $22-\mathrm{kDa}$ protein delivered by OMVs in the development of the biofilm of $H$. pylori TK1402. A biofilm can be defined as a complex tridimensional structure in which cellular aggregates are immersed in a self-produced matrix of extracellular polymeric substances (EPS) (Flemming et al., 2016). Biofilm formation is a multistep regulated process in which cellular adherence, EPS secretion and detachment of bacteria from the maturing biofilm, are controlled by the regulation of several genes (Grande et al., 2014).

Helicobacter pylori cells aggregation and biofilm formation guarantee antibiotic tolerance versus the drugs commonly used in anti-Helicobacter therapy as well as the protection from the host immune system. The variability in the composition and structure of $H$. pylori biofilm suggests the use of multi-targeted or combination therapies. In fact, the tolerance against the antimicrobial drugs might be due to both the slow penetration of drugs through the EPS matrix and the presence of viable but not culturable (VBNC) cells characterized by a metabolic dormancy (Sisto et al., 2000; Dakal et al., 2016). Therefore, the evaluation of $H$. pylori strain susceptibility versus the antimicrobial drugs in vitro, traditionally carried out only on the planktonic phenotype, does not represent a reliable predictor of the efficacy of the antimicrobials in the human stomach (Yonezawa et al., 2015). In fact, Yonezawa et al. (2015) and
Yonezawa et al. (2013) demonstrated that H. pylori biofilm development increased the resistance to clarithromycin at MIC levels by up to 4-fold in 2-day biofilms and to 16-fold in 3day biofilms; thus, H. pylori biofilm phenotype induces the generation of clarithromycin resistance mutations. In conclusion, as previously reported by Yonezawa et al. (2015), the study of new $\mathrm{H}$. pylori eradication strategies using biofilm-dissolving molecules or compounds may provide advantages in resolving H. pylori infections.

For the last few years, the antibiotic resistance represents one of the biggest problems of global health due to the constant increase. More than 50 antibiotics are currently under clinical development, but only a few of them are innovative and can get to the market. The prophylaxis by vaccination is also under preclinical or clinical investigation, but licensed vaccines for $H$. pylori infection are not yet available. Therefore, the therapy improvement remains the only way to fight this infectious disease.

The triple therapy, consisting of a proton-pump inhibitor (PPI) and two different antimicrobials, has been considered the standard therapy for the $H$. pylori eradication for the last 20 years. The increase of the failure rates of the triple therapy recorded in many countries such as those in Europe, as well as Korea, Japan, and China, has been due to an excessive use of antibiotics as well as to the empirical prescription of drugs (Ko et al., 2019). Therefore, both a bismuth-containing quadruple therapy has been recently recommended or clinical studies involving novel potassium-competitive acid blockers (P-CABs instead of PPIs) have been carried out (Mori and Suzuki, 2019) as the first-line treatment of multidrug-resistant $H$. pylori strains, particularly in areas of high clarithromycin resistance (Macías-García et al., 2019). In 2017, the WHO classified the H. pylori resistance to clarithromycin as "a high priority for antibiotic research and development" (Savoldi et al., 2018). The resistance rate to clarithromycin is 30\% in Italy and Japan, and $40 \%$ and $50 \%$ in Turkey and China, respectively (Yonezawa et al., 2013; Ghotaslou et al., 2015; Kocazeybek and Tokman, 2016; Kuo et al., 2017). A new approach should evaluate the use of alternative therapies that does not induce resistance and are effective on sensitive or resistant strain as well.

Based on these considerations, it is necessary to identify an alternative or adjuvant strategy to the standard antibiotic therapy, in order to reduce the development of any antibiotic resistance. Many recent studies report the antimicrobial efficacy of metallic nanomaterials, suggesting their potential use in medical devices, burn dressing, water treatment, and food preservation (Vimbela et al., 2017). Among all types of nanoparticles developed and characterized, silver nanoparticles (AgNPs) gained strong attention due to their inherent characteristic of acting as an antimicrobial agent even in solid state. AgNPs showed a strong antimicrobial activity against several Gram-positive and Gramnegative microorganisms as well as an antibiofilm effect (Sondi and Salopek-Sondi, 2004; Jain et al., 2009; Puca et al., 2019).

More in detail, AgNPs showed to be effective against H. pylori strains at very low concentrations (Amin et al., 2012, 2014; Gurunathan et al., 2015; Saravanakumar et al., 2019). They have also been tested on a large number of continuous 
and immortalized human cell lines in order to define their cytotoxic effect. However, it is worth noting that, due to the source variability and the differences in chemical-physical properties of the nanoparticles used in several studies, the results obtained are not easily comparable. Another important feature of many phytogenic or chemically synthesized types of AgNPs is the presence of surfactants, antioxidants, and/or organic stabilizers (Mathur et al., 2018; Shanmuganathan et al., 2019). To overcome these issues, we have recently synthesized novel Silver Ultra-NanoClusters (SUNCs) (patent pending EP-18181873.3) using a reproducible electrochemical approach. In contrast to conventional AgNPs, our silver solutions are stable in ultrapure water (UPW) and do not contain any surfactant or organic stabilizer. Moreover, due to their exceptional nanosize (average less than $5 \mathrm{~nm}$ ), we named them SUNCs. Several studies indicate that small nanoparticles induce greater cytotoxicity than larger ones (Duran et al., 2010; Riaz et al., 2017; Siddiqi et al., 2018). The smaller size of nanoparticles is related to greater surface area that promotes higher agglomeration around the cell wall with consequent membrane damage (Lu et al., 2019). In general, the higher cytotoxicity of smaller nanoparticles can be explained by different chemical-physical properties occurring when the particle is formed by a lower aggregation of atoms. As an example, we can consider the observed increased ROS production of small nanoparticles as compared to that generated by the greater ones (Hossain et al., 2019). Other mechanisms associated with these silver-containing nanosystems are the disruption of the bacterial membrane, uncoupling of the respiratory electron transport, morphological changes (cytoplasm membrane detachment), DNA replication impairment, and protein expression alteration (Durán et al., 2016; Tang and Zheng, 2018). The aim of the present study was the evaluation of the antimicrobial and antibiofilm activity of these newly synthesized SUNCs, alone and in association, against $H$. pylori strains characterized by a different antibiotic susceptibility pattern. In addition, their cytotoxic effect on AGS cells was also investigated. This is the first report dealing with silver nanosystems endowed with an average dimension inferior to $5 \mathrm{~nm}$ in order to comprehend the further preclinical applications in vivo.

\section{MATERIALS AND METHODS}

\section{Bacterial Strains and Cell Culture}

Eight clinical isolates of $H$. pylori, including two highly resistant to metronidazole (MNZ) ( $\mathrm{MIC}>8 \mathrm{mg} / \mathrm{L}$ ), two resistant to clarithromycin (CLR) $(\mathrm{MIC}>0.5 \mathrm{mg} / \mathrm{L})$, two resistant to both MNZ and CLR, and two CLR, MNZ, and amoxicillin (AMX) susceptible, were tested. The isolated strains have been previously used in other research studies (Brenciaglia et al., 1996; Sisto et al., 2000; Zengin et al., 2018). The study did not require ethical approval, because all the isolates were obtained as part of routine diagnostic microbiology investigations; however, patients with duodenal ulcer or gastritis enrolled at the Microbiology Laboratory of "Luigi Sacco" - ASST Fatebenefratelli Sacco, Milan hospital, gave informed consent for further future studies.
A reference strain of $H$. pylori (ATCC 43504) was used as a control. Antimicrobial drugs were purchased from Sigma-Aldrich (St. Louis, MO, United States) and prepared according to the Clinical and Laboratory Standard Institute (Clinical and Laboratory Standard Institute [CLSI] 2007). The strains were cultured on Columbia agar base (Difco, BD, San Jose, CA, United States) supplemented with 10\% $(v / v)$ horse serum (Seromed, Biochrom, Germany) and $0.25 \%(w / v)$ bacto yeast extract (Difco, BD, San Jose, $\mathrm{CA}$, United States). Plates were incubated for $72 \mathrm{~h}$ at $37^{\circ} \mathrm{C}$ under microaerophilic conditions $\left(85 \% \quad \mathrm{~N}_{2}, \quad 10 \%\right.$ $\mathrm{CO}_{2}, 5 \% \mathrm{O}_{2}$ ).

Human gastric adenocarcinoma AGS ATCC CRL-1739 cell line (American Type Culture Collection, Manassas, VA, United States) was cultured in a 5\% $\mathrm{CO}_{2}$ atmosphere in F-12 medium (HyClone, Logan, UT, United States) supplemented with $10 \%(v / v)$ decomplemented fetal bovine serum (FBS) (EuroClone SpA, Milan, Italy).

\section{Synthesis and Characterization of SUNCs}

Silver Ultra-NanoClusters were electrochemically synthesized by means of an improved synthetic protocol in UPW without stabilizing agents or other chemical components as previously reported (Scotti et al., 2017). The novelty is based on an "ultra small" size without changing the complex set of physical and chemical properties (Z-Potential, Plasmonic UVVis absorbance, concentration, stability in acid $\mathrm{pH}$ ). The method is protected by European Patent pending (EP-18181873.3). The product was a yellow solution with an absorbance maximum at $410 \mathrm{~nm}$, odorless with a $\mathrm{pH}$ of $7-8$, and characterized by good stability (6 months). No change in absorbance and $\lambda_{\max }$ was observed after $1 \mathrm{~h}$ of incubation of SUNCs at $\mathrm{pH} 3.5$ in $0.01 \mathrm{M}$ acetate buffer. A drastic decrease of the plasmonic spectrum absorbance, without change of the $\lambda_{\max }$, was observed after nitric acid treatment $(0.1 \mathrm{M}$, $\mathrm{pH}<1)$ for $10 \mathrm{~min}$ at $25^{\circ} \mathrm{C}$. The complete disappearance of the SUNCs UV-Vis spectrum is obtained after $60 \mathrm{~min}$ of nitric acid $\left(0.1 \mathrm{M}\right.$ final concentration) reaction at $60^{\circ} \mathrm{C}$ (Supplementary Figure S1; Ertürk, 2019). After each synthesis, large nanoclusters were removed by flushing the solution through 0.1- $\mu \mathrm{m}$ syringe filter devices (Whatman CYCLPR) and subsequent centrifugation at $13,023 \times g$ for 15 min. SUNCs were characterized by transmission electron microscopy (TEM) in terms of concentration, shape, and size determination $(75 \mathrm{kV}$ ZEISS 109 equipped with Gatan-Orius SC200W-Model 830.10W TEM CCD Camera). Particle concentration was taken at $75 \mathrm{kV}$ after evaporation of a drop of diluted SUNCs solution (1:5) on 300 mesh formvar-coated nickel grids and confirmed by ionselective electrode (ISE) technique. Evidence of non-spherical shape was reported by TEM at $250,000 \times$ magnification, and the images were elaborated with ImageJ software (ImageJ bundled with Java 1.8.0_172).

Particle numbers and distribution were calculated using a statistical software Origin ver. 9.0; their good stability in the time $(>1$ year $)$ was also verified 
(Scotti et al., 2017). The morphology and the elemental composition of the particles were analyzed by scanning electron microscopy (SEM) using a Phenom xl (Thermo Fisher Scientific, United States) equipped with BDS, SED, and EDS detectors (15 kW of acceleration voltages under high vacuum level).

\section{Antimicrobial Activity of SUNCs}

Minimal inhibitory concentrations (MICs) and minimum bactericidal concentrations (MBCs) were determined by modified broth microdilution method as previously described (Sisto et al., 2009). Briefly, twofold serial dilutions of SUNCs were prepared in MegaCell ${ }^{\mathrm{TM}}$ RPMI-1640 medium (SigmaAldrich, ST Louis, MO, United States) with 3\% (v/v) fetal calf serum (FCS) (HyClone, Logan, UT, United States). H. pylori suspension was inoculated in each well to obtain a final concentration of approximately $5 \times 10^{5} \mathrm{CFU} \times$ well. The 96 -well microtiter plates were incubated at $37^{\circ} \mathrm{C}$ under microaerophilic conditions and examined after $72 \mathrm{~h}$ of incubation. The MBC was determined as the lowest concentration of SUNCs able to kill $99.9 \%$ of the starting inoculum. Aliquots $(100 \mu \mathrm{l})$ of each suspension without visible growth were spotted on Columbia agar plates and incubated at $37^{\circ} \mathrm{C}$ for $3-$ 5 days under microaerophilic conditions. The bactericidal activity of SUNCs was also evaluated by killing curves. The reference strain (ATCC 43504) and a clinical isolate (strain 23) susceptible to metronidazole, clarithromycin, and amoxicillin were used in the liquid culture study in the presence of different SUNCs at $0.5(0.5 \times), 1(1 \times)$, and 2 times $(2 \times)$ the MIC. After 0,24 , and $48 \mathrm{~h}$ of incubation, the number of colony-forming units (CFU) was assessed by plating serial dilution of the samples onto Columbia agar plates. The rate and extent of killing were expressed as viable count $\left(\log _{10}\right.$ $\mathrm{CFU} / \mathrm{ml}$ ) against time.

\section{Combination Effect of Metronidazole and Clarithromycin With SUNCs}

The combination effect of metronidazole and clarithromycin and SUNCs was determined by checkerboard assay and evaluated using fractional inhibitory concentration index (FICI). The inoculum size and the culture conditions were the same as those used for MIC determination. The FICI was calculated from the fractional inhibitory concentration (FIC) values of test compounds and antimicrobials. The FICI $\leq 0.5,>4.0$, and $>0.5-4$ were defined as synergistic, antagonist, and non-synergistic or additive, respectively (Doerne, 2014).

\section{Evaluation of the Minimum Biofilm Eradication Concentration}

The biofilms were developed as previously described (Grande et al., 2011). The antibiofilm effect of each sample was determined by the evaluation of Minimum Biofilm Eradication Concentration (MBEC). The MBEC was defined as the lowest concentration of SUNCs that completely eradicated bacterial biofilm formed in 96-well flat-bottom polystyrene microtiter plates. Briefly, H. pylori ATCC 43504, H. pylori 23, H. pylori $110 \mathrm{R}$, and $H$. pylori $\mathrm{F} 40 / 499$ were grown in BB plus $2 \%$ FCS and $0.3 \%(w / v)$ glucose (Sigma-Aldrich). The ON broth cultures were diluted till $\mathrm{OD}_{600}=0.1$ and diluted $1: 10$ to reach $10^{6}$ $\mathrm{CFU} / \mathrm{ml}$. Two hundred microliters of the diluted broth cultures was inoculated into 96-well flat-bottom polystyrene microtiter plates (Eppendorf, Hamburg, Germany) and incubated at $37^{\circ} \mathrm{C}$ for $48 \mathrm{~h}$ under static conditions as previously described (Ronci et al., 2019). At the end of incubation, the biofilms were rinsed in phosphate-buffered saline (PBS) and SUNCs were added to the mature biofilms at concentrations corresponding to $1 \times$ MIC, $2 \times$ MIC, $3 \times \mathrm{MIC}, 4 \times \mathrm{MIC}$, and $6 \times \mathrm{MIC}$. Controls consisting of (i) $H$. pylori biofilms without the
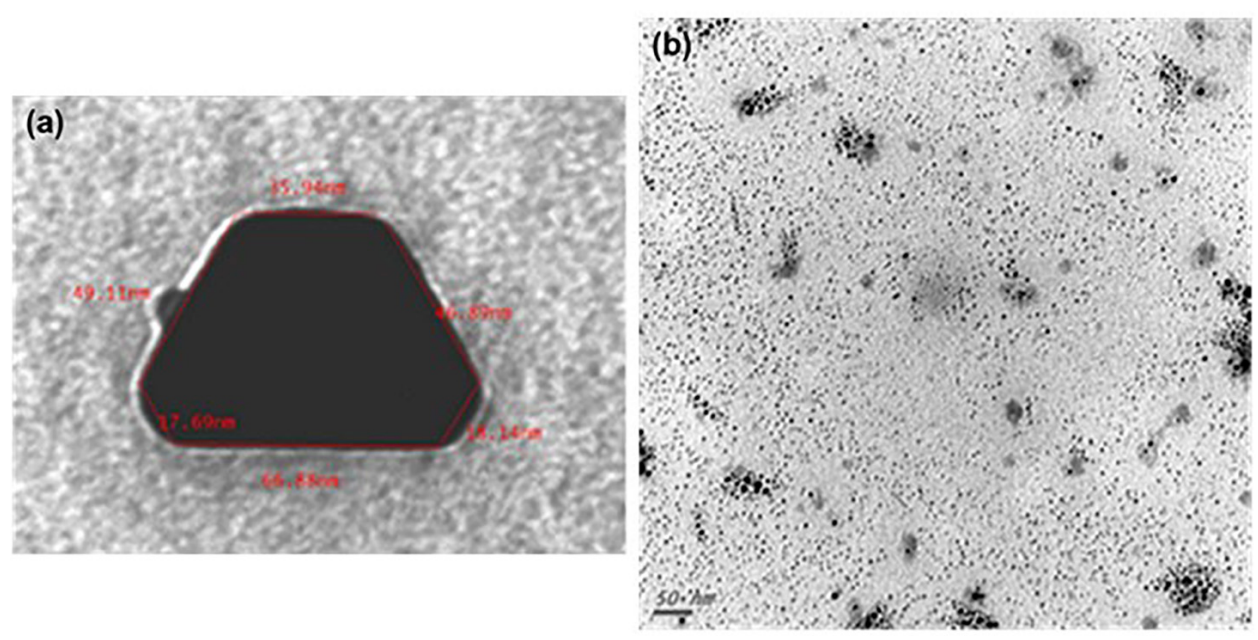

FIGURE 1 | Transmission electron microscopy of SUNCs. SUNCs were electrochemically synthesized in ultrapure water. Large non-spherical nanocluster before filtration. Magnification: 250,000 × (a); ultra-nanoclusters after filtration. A drop of 1:5 diluted stock solution of SUNCs was allowed to evaporate onto 300 mesh formvar-coated nickel grids, and then TEM image was taken at 75 kV by a ZEISS 109 microscope. Scale bar: $50 \mathrm{~nm}$. Magnification: $85,000 \times$ (b). 
addition of SUNCs, (ii) BB plus $0.3 \%(w / v)$ glucose and $2 \%$ The plates were then incubated at $37^{\circ} \mathrm{C}$ for $24 \mathrm{~h}$ under of FCS and SUNCs, and (iii) just medium plus $0.3 \%(w / v)$ glucose and $2 \%$ of FCS were inserted in the experiments. static conditions. The inhibitory effect was measured using

AlamarBlue (AB) assay (Thermo Fisher Scientific, Waltham, MA,

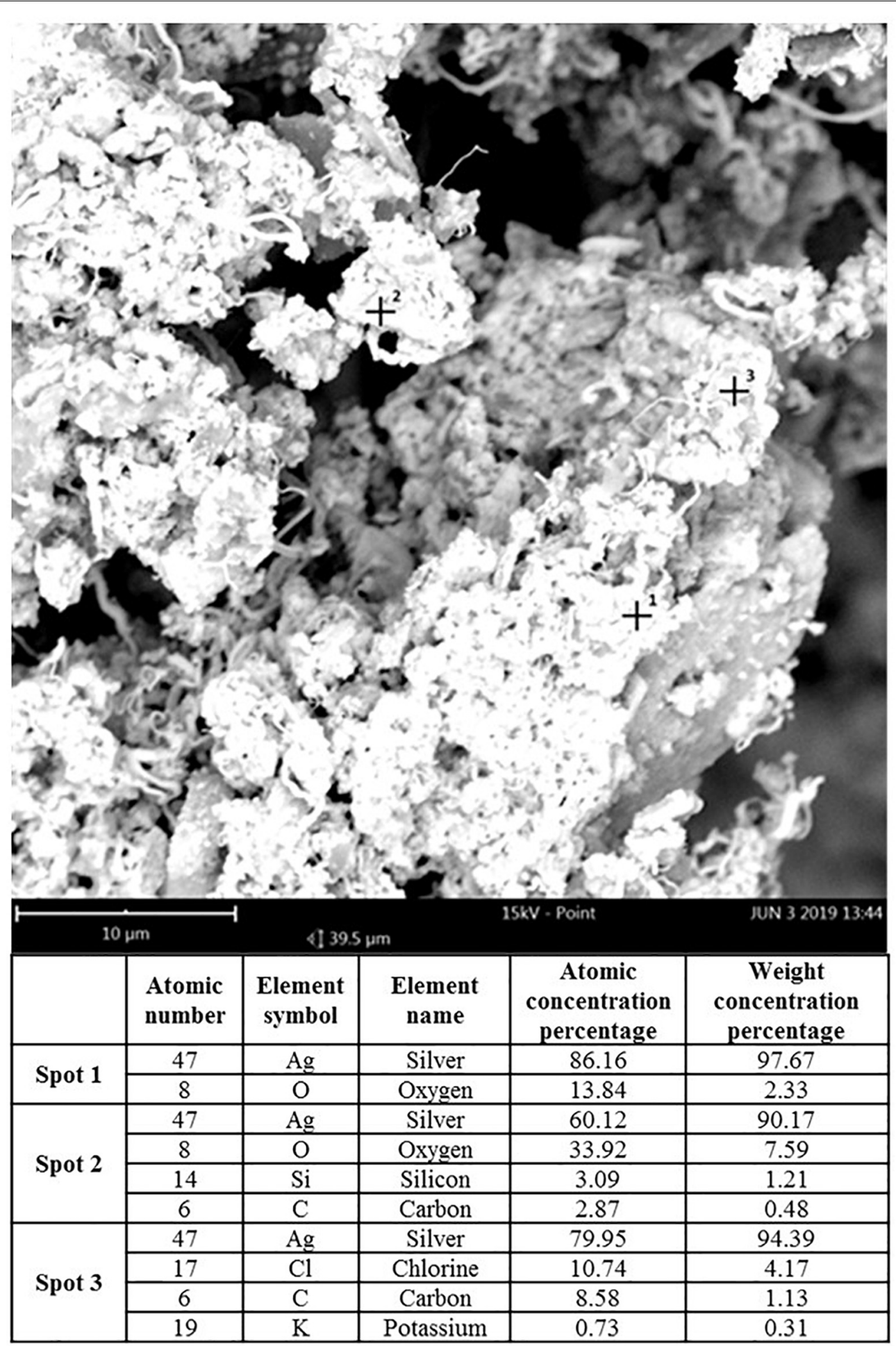

FIGURE 2 | Scanning electron microscopy analysis of SUNCs. Magnification: 85,000× (scale bar: $10 \mu \mathrm{m}-15 \mathrm{kV}$ ). Spots 1, 2, and 3 revealed different distribution of elements in the sample-different phases according to the SEM elemental analysis. 
United States) and CFU count. Three independent experiments were performed in triplicate.

\section{AB Biofilm Eradication Assay}

The biofilms treated with different concentrations of SUNCs (0.32 mg/L, $0.64 \mathrm{mg} / \mathrm{L}, 0.96 \mathrm{mg} / \mathrm{L}, 1.28 \mathrm{mg} / \mathrm{L}$, and $1.92 \mathrm{mg} / \mathrm{L}$ ) were subsequently rinsed with $\mathrm{PBS}$, and $\mathrm{AB}$ was added following the manufacturer's instructions. The plates were incubated for $4 \mathrm{~h}$ at $37^{\circ} \mathrm{C}$ and the absorbance was read. The percentage reduction of $\mathrm{AB}$ in the treated and non-treated samples was calculated using the formula indicated by the manufacturer. The AB MBEC was defined as the lowest concentration of the test sample resulting in $\leq 50 \%$ reduction of $\mathrm{AB}$ and a purplish/blue well, $4 \mathrm{~h}$ after the addition of the $\mathrm{AB}$ as previously demonstrated for other microorganisms (Zengin et al., 2018). Three independent experiments were performed in quadruplicate.

\section{Cell Viability Evaluation Through CFU Count and Live/Dead Staining}

Colony-forming unit enumeration was performed to evaluate bacterial cell viability in the biofilm phenotype after the addition of $\mathrm{AB}$ solution. One hundred microliters of sample solutions taken from the MBEC wells were used for CFU count. Serial dilutions of the stock were performed in PBS ( $\mathrm{pH}$ 7.2), plated on Chocolate Agar (CA) and incubated at $37^{\circ} \mathrm{C}$ under microaerophilic conditions, for 3-5 days. The antibiofilm activity of SUNCs was confirmed by using the Live/Dead BacLight bacterial viability kit (Life Technologies, Carlsbad, CA, United States) according to the manufacturer's instructions, followed by fluorescence microscopy analysis as previously reported (Zengin et al., 2018).

\section{MTT Assay}

Cell toxicity was evaluated using the MTT (3-(4,5dimethylthiazol-2-yl)-2,5-diphenyl-2H-tetrazolium bromide) assay (Mossman, 1983). Briefly, AGS cells seeded in a 96-well microtiter plates at $10^{5} \mathrm{cell} / \mathrm{ml}$ were treated with serial dilution of test compounds for $24 \mathrm{~h}$, using DMSO (Sigma-Aldrich) as control. At the end of incubation, MTT solution (Sigma) diluted in PBS (5 mg/ml) was added, and incubation continued for an additional $3 \mathrm{~h}$ at $37^{\circ} \mathrm{C}$ in the dark. The plates were then read on a microplate reader (Synergy IV, BioTek Instruments, United States) using a test wavelength of $550 \mathrm{~nm}$ and a reference wavelength of $650 \mathrm{~nm}$. The optical density at $650 \mathrm{~nm}$ (OD 650) was subtracted from the OD 550 to eliminate non-specific background. The effect was expressed as percentage of the optical density measured in cultures that did not receive SUNCs (100\% viability).

\section{Statistical Analysis}

The differences in the means of the results between untreated and treated $H$. pylori were analyzed by Student's $t$ test. The probability value of $p \leq 0.05$ was considered significantly different.

\section{RESULTS}

\section{Characterization of SUNCs}

Transmission electron microscopy and ISE analyses indicated that SUNCs were characterized by a non-spherical shape (Figure 1) at concentration of $20.9 \mathrm{mg} / \mathrm{L}$ (yellow solution, pH 78). Statistical evaluation of TEM images demonstrated that the average size of the nanoclusters is $1.83 \mathrm{~nm} \pm 1.57$ (5.366 points, with min and max values of 1.15 and $13.75 \mathrm{~nm}$, respectively). The prevalent abundance of the silver metal $\left(\mathrm{Ag}^{\circ}\right)$ in the formulation was assessed by the typical (UV-Vis) plasmonic resonance spectrum $\left(\lambda_{\max }\right.$ at $\left.410 \mathrm{~nm}\right)$ and by SEM. Analysis of SEM images (Figure 2) indicated the presence of regions with different elemental composition. Three different regions (spots 1 , 2, and 3) showed the presence of different elements: Ag, O, Si, C, $\mathrm{Cl}$, and $\mathrm{K} \cdot \mathrm{Ag}^{\circ}$ was predominant in all the evaluated areas. It is interesting to note that for spots 1 and 2, the second abundant element was oxygen, suggesting the possibility for Ag of being present at different oxidation states. The plasmonic spectrum showed no substantially variation in $0.01 \mathrm{M}$ acetate buffer (Axson et al., 2015; D'souza et al., 2015), indicating that pH 3.5 did not affect the stability and the aggregation state of SUNCs. Only after nitric acid treatment $(\mathrm{pH}<1)$ for $1 \mathrm{~h}$ at $60^{\circ} \mathrm{C}$ was a complete disappearance of the plasmonic spectrum, without a shift of the $\lambda_{\max }$, obtained. It is very likely that these drastic conditions can induce the complete oxidation of metal silver in $\mathrm{Ag}^{+}$without macroaggregate formation (Ertürk, 2019).

TABLE 1 | Anti-Helicobacter pylori activity of SUNCs determined by the microdilution assay.

\begin{tabular}{lccccc}
\hline H. pylori strains & SUNCs MIC/MBC $(\mathbf{m g} / \mathbf{L})$ & MBC/MIC & Antimicrobial susceptibility (MIC mg/L) & References \\
\hline Ro1 & $0.16 / 0.32$ & 2 & MNZ 1; CLR 64; AMX 0.016 & MNZ 128; CLR 0.064; AMX 0.032 & Sengin et al., 2018 \\
ATCC 43504 & $0.32 / 0.32$ & 1 & MNZ 1; CLR 0.064; AMX 0.032 & Sisto et al., 2000 \\
23 & $0.32 / 0.32$ & 1 & MNZ 128; CLR 0.03; AMX 0.016 & Brenciaglia et al., 1996 \\
110R & $0.32 / 0.32$ & 1 & MNZ 2; CLR 4; AMX 0.064 & Zengin et al., 2018 \\
F1 & $0.16 / 0.16$ & 1 & MNZ 1; CLR 0.032; AMX 0.032 & Sisto et al., 2000 \\
190 & $0.16 / 0.32$ & 2 & MNZ 32; CLR 8; AMX 0.016 & Zengin et al., 2018 \\
F40/499 & $0.32 / 0.32$ & 1 & MNZ 64; CLR 0.015; AMX 0.015 & Zengin et al., 2018 \\
F40/442 & $0.32 / 0.32$ & 1 & MNZ 128; CLR 4; AMX 0.064 & Zengin et al., 2018 \\
F34/497 & $0.32 / 0.32$ & 1 & &
\end{tabular}

MNZ, metronidazole; CLR, clarithromycin; $A M X$, amoxicillin. 


\section{Determination of MICs and MBCs}

The antibacterial activity of SUNCs was determined against nine $H$. pylori strains. As shown in Table 1, SUNCs showed antibacterial activity at MIC value ranging from 0.16 to $0.33 \mathrm{mg} / \mathrm{L}$. No amoxicillin-resistant strain was available for this study. In addition, the bactericidal activity was performed by the microdilution method. MBC values were 1 - to 2fold MIC concentrations, demonstrating the bactericidal effects of SUNCs against $H$. pylori strains with different antibiotic susceptibility.

\section{Killing Kinetics}

To evaluate the rate of killing of $H$. pylori by SUNCs, a kinetic study was performed against the reference strain ATCC 43504

(Figure 3A) and the clinical isolate 23 (Figure 3B). The control kinetics showed an exponential growth phase for the first $24 \mathrm{~h}$,

\section{A}

\section{ATCC 43504}

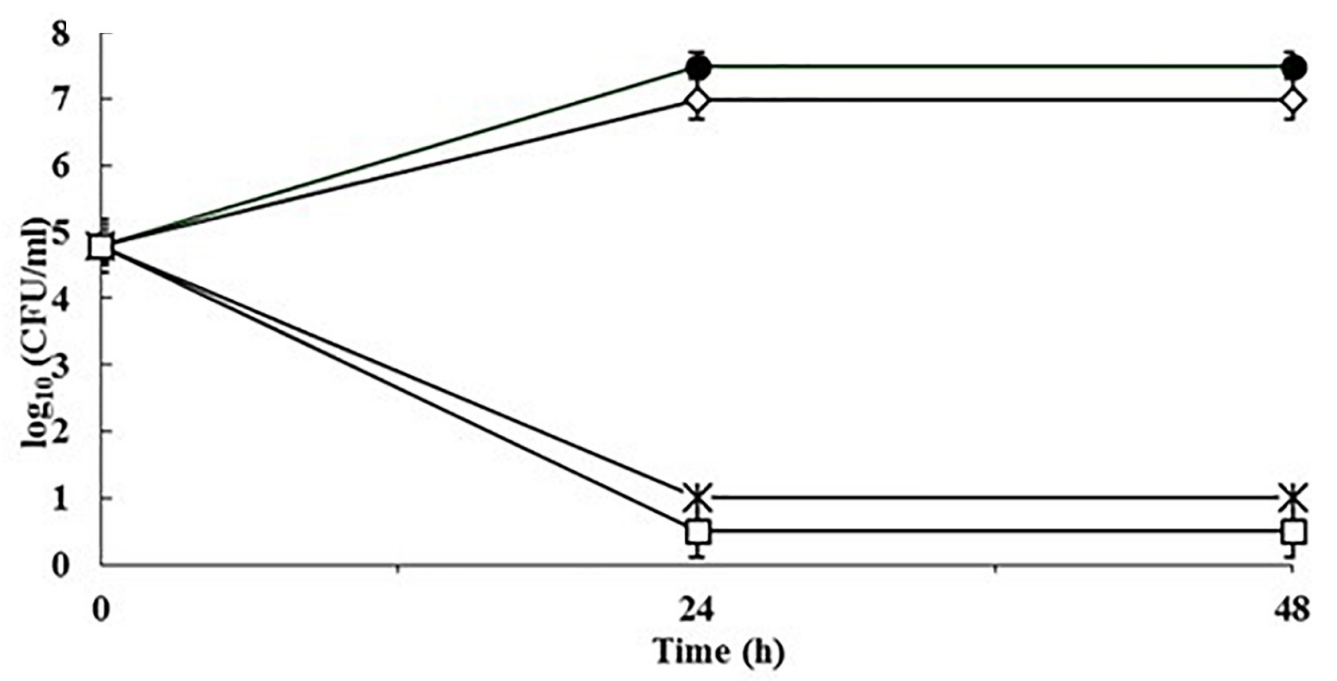

B

\section{Clinical strain $n^{\circ} 23$}

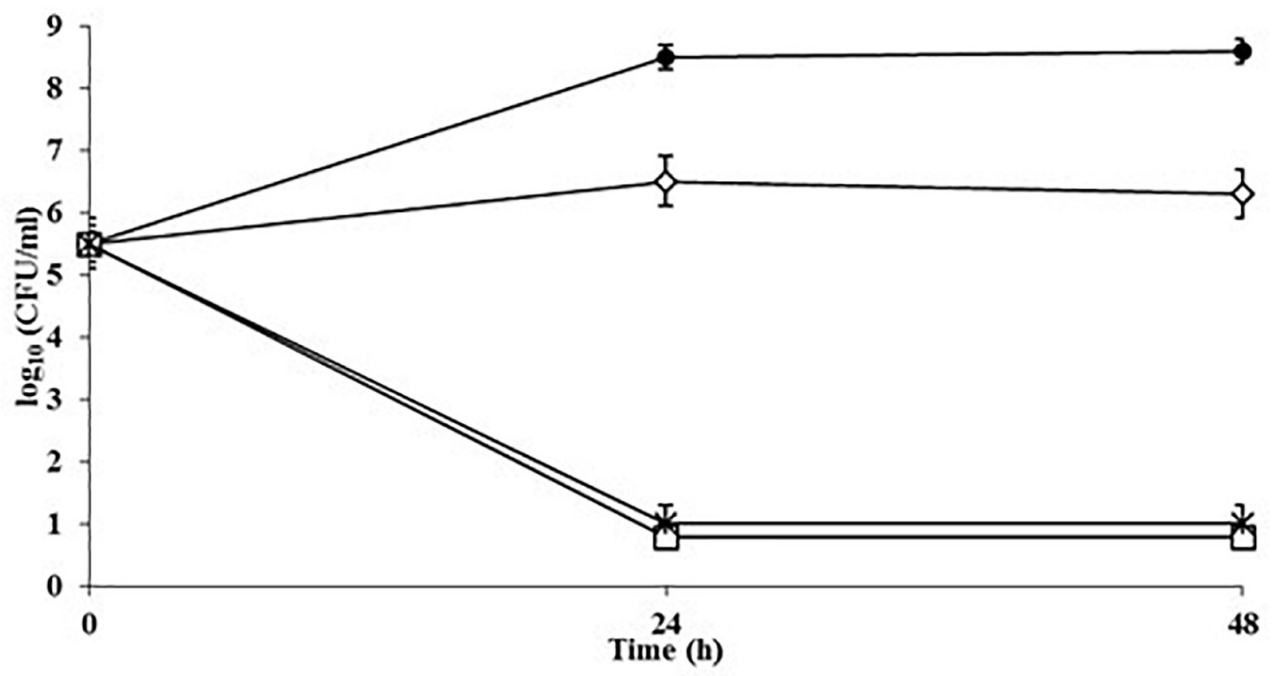

FIGURE 3 | Kinetics of the killing activity of SUNCs against H. pylori ATCC 43504 and the clinical isolate H. pylori 23 by SUNCs. Antibacterial activity was evaluated in RPMI Megacell with 3\% FCS in the presence or absence of the SUNCs concentrations for different time points. The MIC value of H. pylori ATCC 43504 (A) and clinical H. pylori 23 (B) was $0.33 \mathrm{mg} / \mathrm{L}$. The data are expressed as mean CFU \pm SD recovered from three different experiments performed in duplicate. Symbols: filled circle, control; open diamond, $0.5 \times$ MIC; asterisk, $1 \times$ MIC; open square, $2 \times$ MIC. 
and a stationary phase for the following $24 \mathrm{~h}$. SUNCs caused a $\sim 7-\log _{10}$ decrease in cell count at their MIC concentration $(0.33 \mathrm{mg} / \mathrm{L})$ and the total killing within $24 \mathrm{~h}$ for both strains. The limit of detection was $10 \mathrm{CFU} / \mathrm{ml}$.

\section{Combination Effect of Antibiotics With SUNCs}

Metronidazole and clarithromycin are the antimicrobials often used as first-line treatment against $H$. pylori infections. A checkerboard titration assay against two strains of $H$. pylori was performed to verify a possible synergistic effect between SUNCs and both antimicrobial drugs. The reference strain (ATCC 43504) resistant to metronidazole (MIC > $16 \mathrm{mg} / \mathrm{L}$ ) and strain 23 sensitive to clarithromycin, amoxicillin, and metronidazole were selected for this assay. SUNCs showed a value very close to synergism (FICI 0.51 ) with clarithromycin on both strains (Table 2), and with metronidazole on the reference strain (FICI 0.55); a synergistic effect was obtained on clinical $H$. pylori 23 (FICI 0.42) in combination with metronidazole. These results are encouraging for a possible synergistic interaction.

\section{Evaluation of MBEC}

The capability of SUNCs to eradicate the biofilm developed by $H$. pylori after 2 days of incubation was determined by using AB assay, CFU counting, and Live/Dead staining followed by fluorescence microscopy analysis. The anti-biofilm effect of SUNCs was evaluated against $3 \mathrm{H}$. pylori clinical strains characterized by a different antimicrobial susceptibility pattern and versus the reference strain. SUNCs showed a MBEC value of $1.28 \mathrm{mg} / \mathrm{L}$ versus $H$. pylori ATCC 43504 and H. pylori 23, a MBEC value of $0.96 \mathrm{mg} / \mathrm{L}$ against $H$. pylori $110 \mathrm{R}$ and $0.64 \mathrm{mg} / \mathrm{L}$ against H. pylori F40/499. The MBEC was determined by using the AB assay based on resazurin reduction by viable cells, in resorufin, a highly fluorescent red/purple compound (Figures 4A,B). The efficacy of SUNCs on $H$. pylori biofilm eradication was confirmed by both the reduction of CFU counts (Figure 4C) and fluorescence microscopy analysis (Figure 5 and Supplementary Figure S2). SUNCs caused a $\sim 1-\log _{10}$ decrease in cell count at $1.28 \mathrm{mg} / \mathrm{L}$ for H. pylori ATCC 43504 and H. pylori 23 and a $\sim 7-\log _{10}$ and $\sim 4-\log _{10}$ decrease in cell count at $0.64 \mathrm{mg} / \mathrm{L}$ for $H$. pylori $110 \mathrm{R}$ and $H$. pylori F40/499, respectively. The fluorescence microscopy has been used as a qualitative analysis. The images showed a visible disaggregation of the biofilm in all SUNCs-treated strains confirming the CFU reduction (Figure 5 and Supplementary Figure S2). In particular, the addition of SUNCs at concentrations corresponding to the MBEC of the tested strains displayed a detachment of the biofilm or the

TABLE 2 | Checkerboard titration assay of SUNCs in combination with MNZ and CLR.

\begin{tabular}{lcccr}
\hline FIC index & MNZ & FICI & CLR & FICI \\
\hline$\leq 0.5$ (synergy) & Strain 23 & 0.42 & Strain 23 & 0.51 \\
$0.5<$ FIC $\leq 4$ (not & ATCC 43504 & 0.55 & ATCC 43504 & 0.51 \\
synergistic/additive interaction) & & & &
\end{tabular}

presence of few cells, many of which were dead (red fluorescence), attached to the surface of the plates. We speculate that dead cells tend to detach from the surface returning to the planktonic phase. The cells that remain adhered are typically live cells, tenaciously attached and dead cells still trapped in the EPS matrix (Figures 5B,D,F,H and Supplementary Figures S2B,D,F,H). This hypothesis was confirmed by the quantitative analysis based on the CFU counts and $\mathrm{AB}$ assay. On the contrary, the untreated biofilm was characterized by large aggregates of living cells as indicated by the green fluorescence (Figures 5A,C,E, G and Supplementary Figures S2A,C,E,G).

\section{Effects of SUNCs Cells Viability}

The effect of increasing concentrations of SUNCs (from 0.04 to $5.28 \mathrm{mg} / \mathrm{L}$ ) was evaluated by MTT assay (Figure 6). SUNCs at concentrations of $0.04,0.08,0.16$, and $0.33 \mathrm{mg} / \mathrm{L}$ resulted in $100 \%$ viability in AGS cells. A dose-dependent curve was obtained at 0.66 and $1.32 \mathrm{mg} / \mathrm{L}$ with $99 \%$ and $96 \%$ viability, respectively. At $2.64 \mathrm{mg} / \mathrm{L}$, a dramatic decrease of viability was obtained $(1 \%$ viability). For this reason, it was not possible to calculate the $\mathrm{IC}_{50}$. In order to evaluate the effects of SUNCs on different cell lines, MTT assay on HaCaT and HMEC was also performed. A dose-dependent toxicity was observed for HMEC with $\mathrm{IC}_{50}$ of $2.84 \mathrm{mg} / \mathrm{L}$. HaCaT cells showed excellent viability also after the treatment at SUNCs concentration of $5.28 \mathrm{mg} / \mathrm{L}$ (details in Supplementary Material and Supplementary Figure S3).

\section{DISCUSSION}

The antimicrobial effect of different $\mathrm{Ag}^{+}$ion formulations against H. pylori has already been demonstrated in vivo and in vitro, but few studies on the efficacy of AgNPs are present in the literature do date. Very recently, a study about the effect of biocompatible AgNPs against H. pylori MH179988 has been published (Saravanakumar et al., 2019). The authors reported a MIC of $18.14 \mathrm{mg} / \mathrm{L}$, which is 8 to 10 times higher than that found in the present study, highlighting the excellent bactericidal efficacy of SUNCs. Due to the fact that many studies also aimed at analyzing the toxic effects of silver ions on human cells and in in vivo systems (acute exposure, bioavailability, and bioaccumulation) (Stensberg et al., 2011) and that the results often correlated the AgNP size and shape to toxicity and ADME properties, we proposed the synthesis and characterization of SUNCs endowed with dimensions $<5 \mathrm{~nm}$. The SEM analysis indicates the presence, at the clusters' surface, of different Ag oxidative states whose higher reactivity might explain the present results, although further investigations are needed to better assess the peculiar chemical-physical properties of these SUNCs.

The new silver formulation showed to be very effective against different $H$. pylori strains tested with also a synergistic/additive effect when combined with MNZ and CLR. In comparison with MNZ alone, SUNCs were found to be active at their MIC value approximately three- or sixfold lower than that of MNZ-sensitive strains (MIC MNZ = $1 \mathrm{mg} / \mathrm{L}$ ). In the AGS cell model, the MTT assay showed that SUNCs were toxic at $2.62 \mathrm{mg} / \mathrm{L}, \sim 4$ 
A

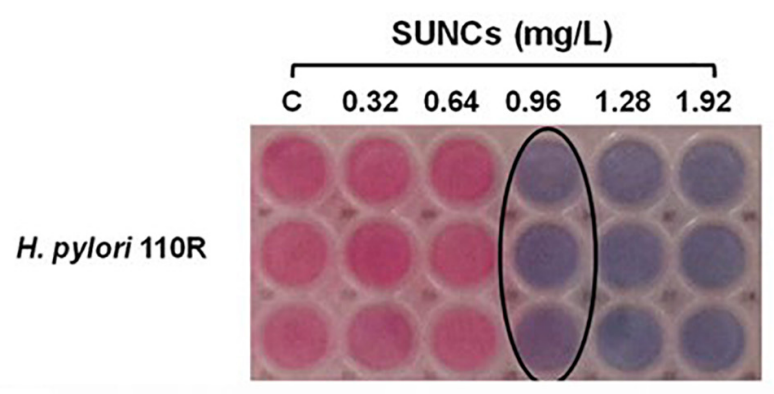

B

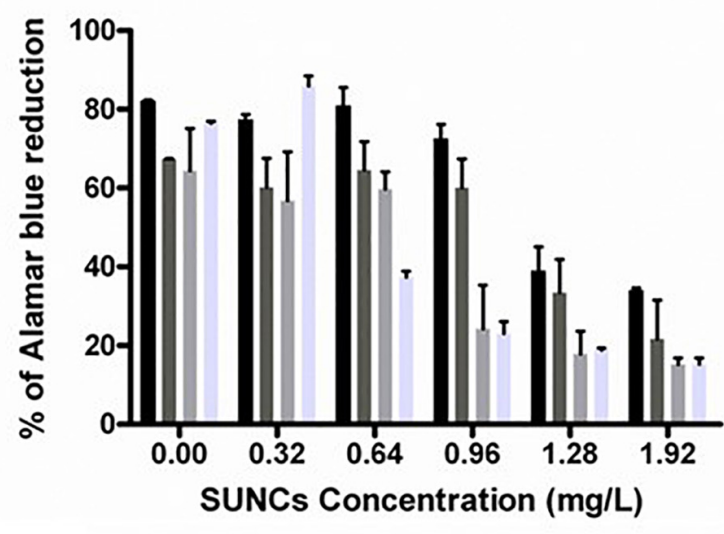

H. pylori ATCC 43504

H. pylori 23

$\square$ H. pylori 110R

H. pylori F40/499

C

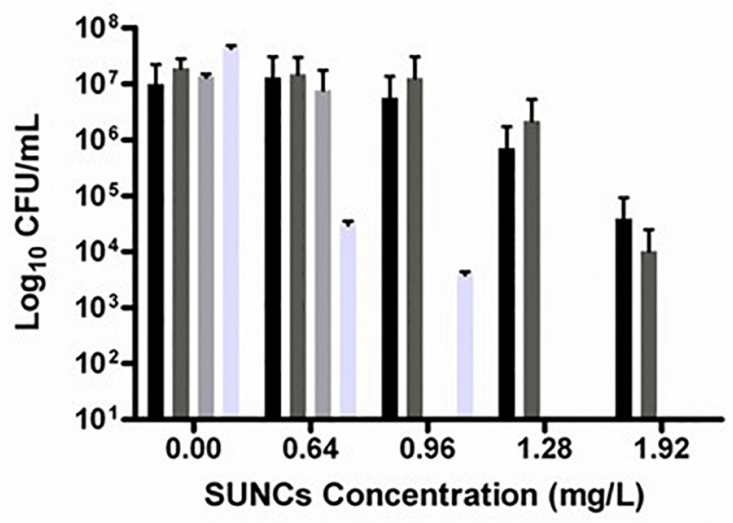

H. pylori ATCC 43504

H. pylori 23

H. pylori 110R

H. pylori F40/499

FIGURE 4 | The determination of the Minimum Biofilm Eradication Concentration (MBEC) against the $\mathrm{H}$. pylori biofilm was evaluated by using the AB assay and the CFU counting. Representative image of colorimetric MBEC evaluation by using AB. The black circle indicates the MBEC at 0.96 mg/L against $H$. pylori $110 R$ (A). The plot displays the percent reduction of $\mathrm{AB}$ in $\mathrm{H}$. pylori biofilms at different concentrations of SUNCs compared to the corresponding untreated biofilms (B). CFU count of SUNCs-treated and untreated biofilms $\mathbf{( C )}$. Data are presented as the mean of three replicates of three independent experiments. Controls correspond to 0 mg/L.

and $3 \log _{2}$ dilutions higher than their MIC and/or MBC values, respectively. These results clearly corroborated the limited cell toxicity of our SUNCs with respect to commercially available AgNPs characterized by greater dimensions, as reported in the literature (Duran et al., 2010).
It has been widely demonstrated that $H$. pylori develops biofilm both in vitro and in vivo (Cellini et al., 2005, 2008; Carron et al., 2006; Grande et al., 2015). As reported by Koo et al. (2017) the biofilm, initially defined as the "arcane behavior of bacterial populations," is considered today as a "principal virulence 


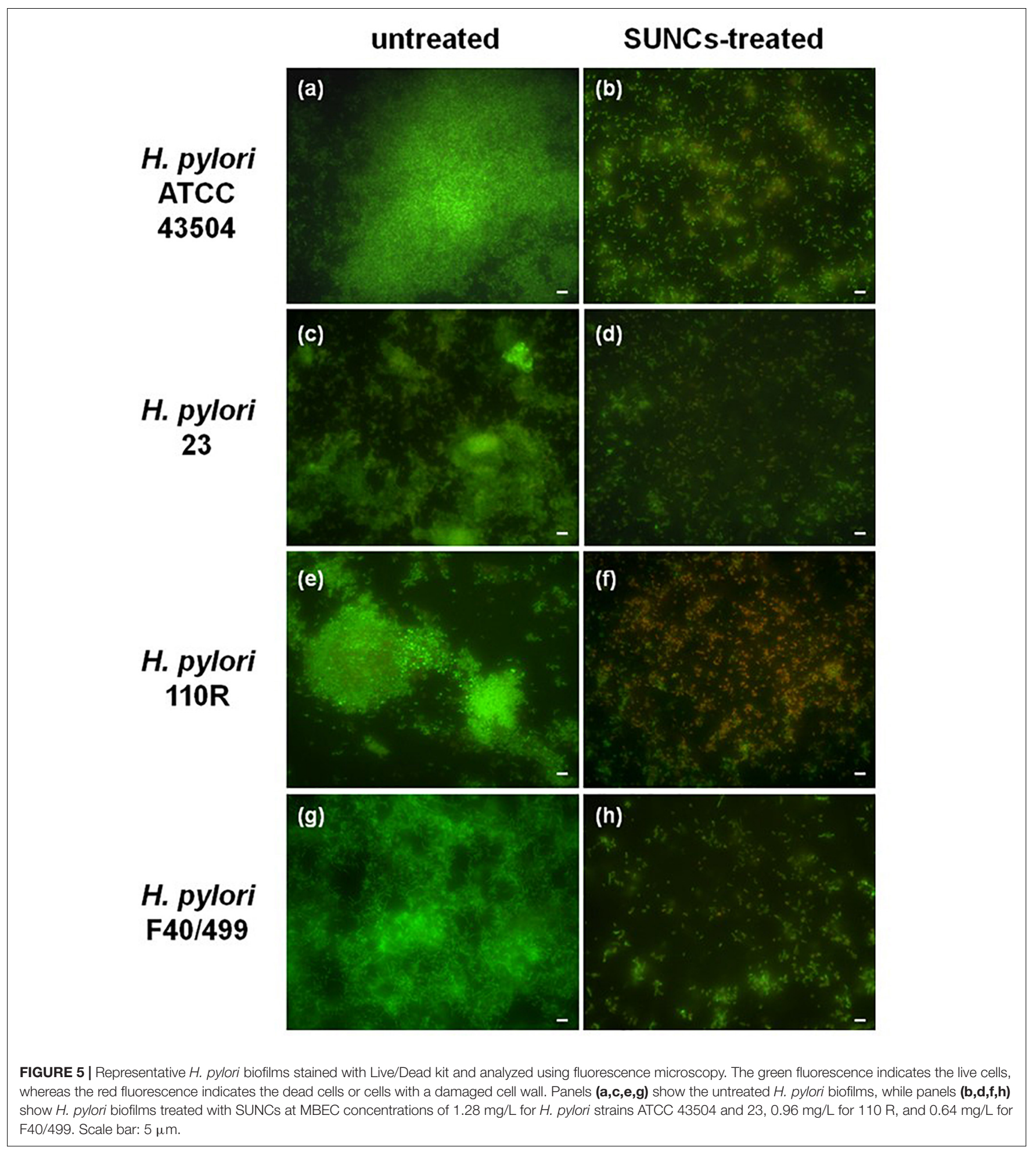

factor in many localized chronic infections." Biofilm infections commonly recur after long periods of clinical quiescence, and the key role of the EPS biofilm matrix in ensuring antimicrobial tolerance to biofilms is widely demonstrated (Koo et al., 2017).

Among the common features of microbial biofilms, there is the adherence. In fact, microorganisms adhere to both abiotic materials such as plastic, metals, ceramics, etc., and biotic surfaces such as tooth enamel, bone, skin, intestinal, vaginal mucosa, and connective tissues, but also gastric mucosa as demonstrated by Carron et al. (2006) who showed H. pylori biofilm on human gastric mucosa. The multifactorial nature of biofilm development and drug tolerance dictates important 


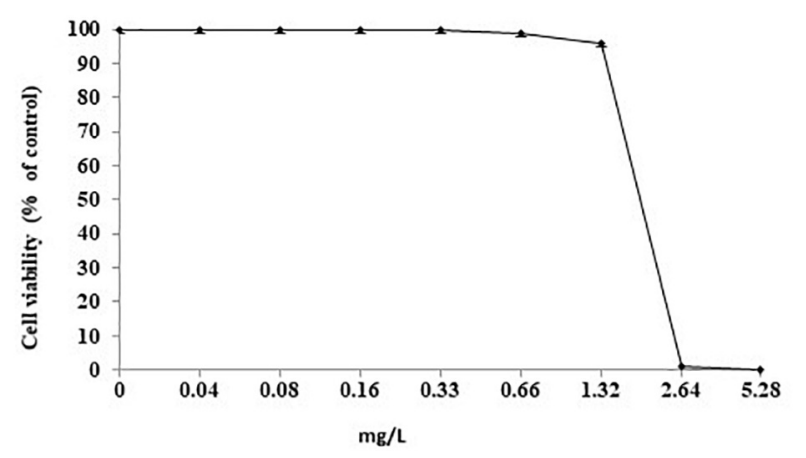

FIGURE 6 | Cell viability after treatment with SUNCs by MTT assay. AGS cells were incubated for $24 \mathrm{~h}$ with different doses of SUNCs in F12 medium. The effect is expressed as percentage of the optical density (OD) \pm SD measured in non-treated cultures (100\% viability).

choices in the use of conventional antimicrobial drugs and dictates the need for multi-target or combinatorial therapies, particularly for $H$. pylori infections often associated with multidrug-resistant strains toward antibiotics commonly used in therapy such as clarithromycin. Therefore, the identification of alternative therapies also associated with the use of antibiotics commonly administered in clinical practice is necessary. The microbial community of the biofilm may develop tolerance to the antibiotics using different mechanisms such as the bacterial conversion from the culturable status into a VBNC status (Sisto et al., 2000), or the development of molecular pathways that promote the bacterial persistence and survival (Flemming et al., 2016). The efficacy of SUNCs has been tested to evaluate its possible application for the treatment of $H$. pylori infections associated with the biofilm development. The capability of SUNCs to eradicate a 2-day preformed biofilm is probably due to nanoparticle penetration through the biofilm EPS matrix, where they are less susceptible to modifications compared to common drugs (Dakal et al., 2016). On the other hand, Gurunathan et al. (2015) demonstrated that AgNPs, with an average size of $20 \mathrm{~nm}$, caused dose-dependent decrease in cell viability and biofilm formation as well as DNA fragmentation in $H$. pylori and Helicobacter felis. Moreover, the data obtained showed the capability of SUNCs to kill planktonic cells and to eradicate the biofilms developed by all strains analyzed, regardless of their pattern of sensitivity to antimicrobial drugs. The fluorescence microscopy images show the presence of few cells adhered to the plate surface in the SUNCs-treated samples, suggesting that the SUNCs disrupt the biofilm. We hypothesize that SUNCs induce cell death, promoting the cell detachment from the surface. The few remaining cells, in fact, are live cells tenaciously attached to the surface, or dead cells trapped in the EPS matrix. The use of SUNCs as antimicrobial could reduce the drug resistance; therefore, they could be used in combination with antimicrobial drugs, leading also to a decrease in human cell toxicity due to the reduction of the dosage. SUNCs could also be considered a carrier for drug delivery as previously reported (Sharvil et al., 2009). Furthermore, SUNCs at $1.32 \mathrm{mg} / \mathrm{L}$ killed $100 \%$ of bacteria with $100 \%$ viability of AGS cells. Better results were obtained with $\mathrm{HaCaT}$ cells that did not show any toxic effect at all concentrations tested (Supplementary Figure S3). Many studies report the low toxicity of AgNPs on different cell lines (Ivask et al., 2014; Kanipandian et al., 2014; Chhibber et al., 2017). Although in vitro, these results are very encouraging and suggest differences in the toxicity mechanisms of SUNCs in different biological systems. In addition, we showed that SUNCs are about 10 -fold less toxic in mammalian than in bacterial cells, suggesting different toxic mechanisms toward different biological systems. A recent review (Ullah Khan et al., 2018) summarized the toxic effects of AgNPs against bacteria, humans, fungi, viruses, and protozoa. In general, low amount of AgNPs has excessive potential against microorganisms, while at higher concentrations $(>10 \mu \mathrm{M})$, they are toxic to mammals. Conversely, other studies report that humans can tolerate the assumption up to $16 \mathrm{mg}$ with low adverse effects (Kim et al., 2012, 2013; Amin et al., 2014), or propose nanosilver as a pharmaceutical agent that is nontoxic for humans (Lansdown, 2006). These findings, together with the results reported here, strongly support the idea that a possible SUNCs therapy in vivo against $H$. pylori infection could be characterized by limited unwanted side effects (Ottoni et al., 2019; Rodrigues et al., 2019). Indeed, the absorption of AgNPs and their toxicity on human intestinal cells have been monitored by Böhmert et al. (2014). The results suggest that AgNPs may overcome the gastrointestinal juices in their particulate form without forming large quantities of aggregates. Consequently, the authors presumed that the particles can reach the intestinal epithelial cells after ingestion with only a slight reduction in their cytotoxic potential. Furthermore, a recent review (McClements and Xiao, 2017) summarized the factors affecting the gastrointestinal fate and toxicity of organic and inorganic food-grade nanoparticles. Animal studies (Kim et al., 2008; Gaillet and Rouanet, 2015 Hendrickson et al., 2016) corroborated that AgNPs can be absorbed by the gastrointestinal tract into the systemic circulation, and then be distributed throughout various organs. However, only a small fraction $(<1 \%)$ of ingested AgNPs typically accumulate in tissues, which suggests that the majority of them were excreted in the feces or urine (Hendrickson et al., 2016). At the levels used in that study (2000 and $250 \mathrm{mg} / \mathrm{kg}$ body weight for single and multiple doses, respectively), no toxicity of the AgNPs was found after oral gavage. Another rat feeding study reported no major toxic effects of ingestion of AgNPs over a 28 -day period $(30,300$, and $1000 \mathrm{mg} / \mathrm{kg}$ day), but that there was some slight liver damage at the highest levels used (Kim et al., 2008). These results could be a good starting point in order to relate the concentrations that should be delivered in vivo with the effective concentrations observed here in vitro and, in the future, in vivo pharmacokinetic assays will be performed to assess the clinical efficacy and toxicity in a more complex model. To the best of our knowledge, this is the first study reporting the antimicrobial and anti-biofilm effects against $H$. pylori of SUNCs with dimensions smaller than $5 \mathrm{~nm}$ and synthesized in UPW. SUNCs could represent a novel strategy for the 
treatment of $H$. pylori infections especially in cases of multidrug resistance or biofilm-producing strains. Although the strains used in this study have different antibiotic susceptibility profiles, further investigations on a greater collection of isolates with established diverse genetic backgrounds are also to be considered. Although the synergistic activity of SUNCs in association with well-established antimicrobial drugs was performed versus two strains, the data obtained suggest the potential use of SUNCs in combination therapy with traditional antibiotics in order to improve the management of $H$. pylori infection. Further, in vivo pharmacokinetic assays will be performed to assess the clinical efficacy and toxicity in a more complex model.

\section{DATA AVAILABILITY STATEMENT}

All datasets generated for this study are included in the article/Supplementary Material.

\section{AUTHOR CONTRIBUTIONS}

FS and RG designed, interpreted the data, and wrote the article. FS and VP performed the experimental work and acquisition of data. MR, SC, and LS synthesized the nanoparticles and performed the characterization and SEM/TEM analyses. GM

\section{REFERENCES}

Amin, M., Anwar, F., Janjua, M. R., Iqbal, M. A., and Rashid, U. (2012). Green synthesis of silver nanoparticles through reduction with Solanum xanthocarpum L. berry extract: characterization, antimicrobial and urease inhibitory activities against Helicobacter pylori. Int. J. Mol. Sci. 13, 9923-9941. doi: 10.3390/ijms13089923

Amin, M., Hameed, S., Ali, A., Anwar, F., Shahid, S. A., Shakir, I., et al. (2014). Green synthesis of silver nanoparticles: structural features and in vivo and in vitro therapeutic effects against Helicobacter pylori induced gastritis. Bioinorg. Chem. Appl. 2014:135824.

Axson, J. L., Stark, D. I., Bondy, A. L., Capracotta, S. S., Maynard, A. D., Philbert, N. A., et al. (2015). Rapid kinetics of size and $\mathrm{pH}$-dependent dissolution and aggregation of silver nanoparticles in simulated gastric fluid. J. Phys. Chem. C 119, 20632-20641. doi: 10.1021/acs.jpcc.5b03634

Böhmert, L., Girod, M., Hansen, U., Maul, R., Knappe, P., Niemann, B., et al. (2014). Analytically monitored digestion of silver nanoparticles and their toxicity on human intestinal cells. Nanotoxicology 8, 631-642. doi: 10.3109/ 17435390.2013 .815284

Brenciaglia, M. I., Fornara, A. M., Scaltrito, M. M., and Dubini, F. (1996). "In vitro" development of metronidazole, erythromycin, amoxicillin and gentamicin resistance in Helicobacter pylori. Int. J. Antimicrob. Agents 6, 223-226. doi: 10.1016/0924-8579(95)00040-2

Carron, M. A., Tran, V. R., Sugawa, C., and Coticchia, J. M. (2006). Identification of Helicobacter pylori biofilms in human gastric mucosa. J. Gastrointest. Surg. 10, 712-717. doi: 10.1016/j.gassur.2005.10.019

Cellini, L., Grande, R., Di Campli, E., Traini, T., Di Giulio, M., Lannutti, S. N., et al. (2008). Dynamic colonization of Helicobacter pylori in human gastric mucosa. Scand. J. Gastroenterol. 43, 178-185.

Cellini, L., Grande, R., Traini, T., Di Campli, E., Di Bartolomeo, S., Di Iorio, D., et al. (2005). Biofilm formation and modulation of $l u x S$ and $r p o D$ expression by Helicobacter pylori. Biofilms 2, 119-127.

Chhibber, S., Gondil, V. S., Sharma, S., Kumar, M., Wangoo, N., and Sharma, R. K. (2017). A novel approach for combating Klebsiella pneumoniae biofilm analyzed the data and performed the statistical analysis. RM and AA critically revised the work and the final manuscript. RG funded the project. All authors contributed to the article and approved the submitted version.

\section{FUNDING}

This work was supported by the Ministero Italiano dell'Università e della Ricerca (MIUR) FAR 2018 Grant, held by RG.

\section{ACKNOWLEDGMENTS}

This study was presented in part at the XXXIInd International Workshop of the European Helicobacter \& Microbiota Study Group, Innsbruck, Austria, 2019 (Poster P1.18). We are grateful to Dr. Nicole Cellucci and Dr. Maurizia Di Girolamo for their excellent technical assistance.

\section{SUPPLEMENTARY MATERIAL}

The Supplementary Material for this article can be found online at: https://www.frontiersin.org/articles/10.3389/fmicb. 2020.01705/full\#supplementary-material

using histidine functionalized silver nanoparticles. Front. Microbiol. 8:1104. doi: $10.3389 /$ fmicb.2017.01104

Clinical and Laboratory Standard Institute [CLSI] (2007). Performance Standards for Antimicrobial Susceptibility Testing. Seventeenth Informational Supplement M100-S17, Vol. 27. Wayne, PA: Clinical and Laboratory Standard Institute.

Cole, S. P., Harwood, J., Lee, R., She, R., and Guiney, D. G. (2004). Characterization of monospecies biofilm formation by Helicobacter pylori. J. Bacteriol. 186, 3124-3132. doi: 10.1128/jb.186.10.3124-3132.2004

Dakal, T. C., Kumar, A., Majumdar, R. S., and Yadav, V. (2016). Mechanistic basis of antimicrobial actions of silver nanoparticles. Front. Microbiol. 7:1831. doi: $10.3389 /$ fmicb.2016.01831

Doerne, C. D. (2014). When does 2 plus 2 equal 5? A review of antimicrobial synergy testing. J. Clin. Microbiol. 52, 4124-4128. doi: 10.1128/jcm.01121-14

D’souza, S. L., Pati, R., and Kailasa, S. K. (2015). Ascorbic acid-functionalized $\mathrm{Ag}$ NPs as a probe for colorimetric sensing of glutathione. Appl. Nanosci. 5, 747-753. doi: 10.1007/s13204-014-0371-9

Durán, N., Durán, M., de Jesus, M. B., Seabra, A. B., Fávaro, W. J., and Nakazato, G. (2016). Silver nanoparticles: a new view on mechanistic aspects on antimicrobial activity. Nanomedicine 12, 789-799. doi: 10.1016/j.nano.2015.11.016

Duran, N., Marcato, P. D., De Conti, R., Alves, O. L., Costa, F. T. M., and Brocchi, M. (2010). Potential use of silver nanoparticles on pathogenic bacteria, their toxicity and possible mechanisms of action. J. Braz. Chem. Soc. 21, 949-959. doi: 10.1590/s0103-50532010000600002

Ertürk, A. S. (2019). Controlled production of monodisperse plant-mediated AgNP catalysts using microwave chemistry: a desirability-function-based multipleresponse optimization approach. Chem. Select 4, 9300-9308. doi: 10.1002/slct. 201902197

Eshraghian, A. (2014). Epidemiology of Helicobacter pylori infection among the healthy population in Iran and countries of the Eastern Mediterranean Region: a systematic review of prevalence and risk factors. World J. Gastroenterol. 20, $17618-17625$.

Flemming, H. C., Wingender, J., Szewzyk, U., Steinberg, P., Rice, S. A., and Kjelleberg, S. (2016). Biofilms: an emergent form of bacterial life. Nat. Rev. Microbiol. 14, 563-575. doi: 10.1038/nrmicro.2016.94 
Gaillet, S., and Rouanet, J. M. (2015). Silver Nanoparticles: their potential toxic effects after oral exposure and underlying mechanisms - a review. Food Chem. Toxicol. 77, 58-63. doi: 10.1016/j.fct.2014.12.019

Ghotaslou, R., Leylabadlo, H. E., and Asl, Y. M. (2015). Prevalence of antibiotic resistance in Helicobacter pylori: a recent literature review. World J. Methodol. $5,164-174$.

Grande, R., Di Giulio, M., Bessa, L. J., Di Campli, E., Baffoni, M., Guarnieri, S., et al. (2011). Extracellular DNA in Helicobacter pylori biofilm: a backstairs rumour. J. Appl. Microbiol. 110, 490-498. doi: 10.1111/j.1365-2672.2010.04911.x

Grande, R., Di Giulio, M., Di Campli, E., Di Bartolomeo, S., and Cellini, L. (2010). A model of Helicobacter pylori persistence in a case of gastric cancer. New Microbiol. 33, 343-349.

Grande, R., Di Marcantonio, M. C., Robuffo, I., Pompilio, A., Celia, C., Di Marzio, L., et al. (2015). Helicobacter pylori ATCC 43629/NCTC 11639 outer membrane vesicles (OMVs) from biofilm and planktonic phase associated with extracellular DNA (eDNA). Front. Microbiol. 6:1369. doi: 10.3389/fmicb.2015. 01369

Grande, R., Nistico, L., Sambanthamoorthy, K., Longwell, M., Iannitelli, A., Cellini, L., et al. (2014). Temporal expression of agrB, $\operatorname{cidA}$, and alsS in the early development of Staphylococcus aureus UAMS-1 biofilm formation and the structural role of extracellular DNA and carbohydrates. Pathog. Dis. 70, $414-422$.

Gurunathan, S., Jeong, J. K., Han, J. W., Zhang, X. F., Park, J. H., and Kim, J. H. (2015). Multidimensional effects of biologically synthesized silver nanoparticles in Helicobacter pylori, Helicobacter felis, and human lung (L132) and lung carcinoma A549 cells. Nanoscale Res. Lett. 10:35.

Hendrickson, O. D., Klochkov, S. G., Novikova, O. V., Bravova, I. M., Shevtsova, E. F., Safenkova, I. V., et al. (2016). Toxicity of nanosilver in intragastric studies: biodistribution and metabolic effects. Toxicol. Lett. 241, 184-192. doi: 10.1016/ j.toxlet.2015.11.018

Hooi, J. K. Y., Lai, W. Y., Ng, W. K., Suen, M. M. Y., Underwood, F. E., Tanyingoh, D., et al. (2017). Global prevalence of Helicobacter pylori infection: systematic review and meta-analysis. Gastroenterology 153, 420-429.

Hossain, M. M., Polash, S. A., Takikawa, M., Shubhra, R. D., Saha, T., Islam, Z., et al. (2019). Investigation of the antibacterial activity and in vivo cytotoxicity of biogenic silver nanoparticles as potent therapeutics. Front. Bioeng. Biotechnol. 7:239. doi: 10.3389 /fbioe.2019.00239

Hu, Y., Zhu, Y., and Lu, N. H. (2017). Novel and effective therapeutic regimens for Helicobacter pylori in an era of increasing antibiotic resistance. Front. Cell Infect. Microbiol. 7:168. doi: 10.3389/fcimb.2017.00168

International Agency for Research on Cancer (IARC) (1994). "Working group on the evaluation of carcinogenic risks to humans," in Proceedings of the Schistosomes, Liver Flukes and Helicobacter Pylori. IARC Working Group on the Evaluation of Carcinogenic Risks to Human, 7-14 June 1994, Lyon. Vol. 61, 1.

Ivask, A., Kurvet, I., Kasemets, K., Blinova, I., Aruoja, V., Suppi, S., et al. (2014). A size-dependent toxicity of silver nanoparticles to bacteria, yeast, algae, crustaceans and mammalian cells In Vitro. PLoS One 9:e102108. doi: 10.1371/ journal.pone. 0102108

Jain, J., Arora, S., Rajwade, J. M., Omray, P., Khandelwal, S., and Paknikar, K. M. (2009). Silver nanoparticles in therapeutics: development of an antimicrobial gel formulation for topical use. Mol. Pharm. 6, 1388-1401. doi: 10.1021/ mp900056g

Kanipandian, N., Kannan, S., Ramesh, R., Subramanian, P., and Thirumurugan, R. (2014). Characterization, antioxidant and cytotoxicity evaluation of green synthesized silver nanoparticles using Cleistanthus collinus extract as surface modifier. Mater. Res. Bull. 49, 494-502. doi: 10.1016/j.materresbull.2013.09.016

Kim, J. S., Song, K. S., Sung, J. H., Ryu, H. R., Choi, B. G., Cho, H. S., et al. (2013). Genotoxicity, acute oral and dermal toxicity, eye and dermal irritation and corrosion and skin sensitization evaluation of silver nanoparticles. Nanotoxicology 7, 953-960. doi: 10.3109/17435390.2012.676099

Kim, T., Kim, M., Park, H., Shin, U. S., Gong, M., and Kim, H. (2012). Sizedependent cellular toxicity of silver nanoparticles. J. Biomed. Mater. Res. A 100, 1033-1043.

Kim, Y. S., Kim, J. S., Cho, H. S., Rha, D. S., Kim, J. M., Park, J. D., et al. (2008). Twenty-eight-day oral toxicity, genotoxicity, and gender-related tissue distribution of silver nanoparticles in sprague-dawley rats. Inhal. Toxicol. 20, 575-583. doi: 10.1080/08958370701874663
Ko, S. W., Kim, Y. J., Chung, W. C., and Lee, S. J. (2019). Bismuth supplements as the first-line regimen for Helicobacter pylori eradication therapy: systemic review and meta-analysis. Helicobacter 24:e12565. doi: 10.1111/hel.12565

Kocazeybek, B., and Tokman, H. B. (2016). Prevalence of primary antimicrobial resistance of H. pylori in Turkey: a systematic review. Helicobacter 21, 251-260. doi: $10.1111 /$ hel.12272

Koo, H., Allan, R. N., Howlin, R. P., Stoodley, P., and Hall-Stoodley, L. (2017), Targeting microbial biofilms: current and prospective therapeutics strategies. Nat. Rev. Microbiol. 15, 740-755. doi: 10.1038/nrmicro.2017.99

Kosunen, T. U., Pukkala, E., Sarna, S., Seppälä, K., Aromaa, A., Knekt, P., et al. (2011). Gastric cancers in Finnish patients after cure of Helicobacter pylori infection: a cohort study. Int. J. Cancer 128, 433-439. doi: 10.1002/ijc.25337

Kuo, Y. T., Liou, J. M., El-Omar, E. M., Wu, J. Y., Leow, A. H. R., Goh, K. L., et al. (2017). Primary antibiotic resistance in Helicobacter pylori in the Asia-Pacific region: a systematic review and meta-analysis. Lancet Gastroenterol. Hepatol. 2, 707-715. doi: 10.1016/s2468-1253(17)30219-4

Lansdown, A. (2006). Biofunctional Textiles and Skin, Vol. 33. Basel: Karger Publisher, 17-34. doi: 10.1159/isbn.978-3-318-01349-8

Lu, J., Zhang, S., Gao, S., Wang, P., Bond, P. L., and Guo, J. (2019). New insights of the bacterial response to exposure of differently sized silver nanomaterials. Water Res. 169:115205. doi: 10.1016/j.watres.2019.115205

Macías-García, F., Bastón-Rey, I., de la Iglesia-García, D., Calviño-Suárez, C., Nieto-García, L., and Domínguez-Muñoz, J. E. (2019). Bismuth-containing quadruple therapy versus concomitant quadruple therapy as first-line treatment for Helicobacter pylori infection in an area of high resistance to clarithromycin: a prospective, cross-sectional, comparative, open trial. Helicobacter 24:12546.

Mathur, P., Jha, S., Ramteke, S., and Jain, N. K. (2018). Pharmaceutical aspects of silver nanoparticles. Artif. Cells Nanomed. Biotechnol. 46(Suppl. 1.), 115-126. doi: $10.1080 / 21691401.2017 .1414825$

McClements, D. J., and Xiao, H. (2017). Is nano safe in foods? Establishing the factors impacting the gastrointestinal fate and toxicity of organic and inorganic food-grade nanoparticles. NPJ Sci. Food 1:6. doi: 10.1038/s41538-017-0005-1

Mori, H., and Suzuki, H. (2019). Role of acid suppression in acid-related diseases: proton pump inhibitor and potassium-competitive acid blocker. J. Neurogastroenterol. Motil. 25, 6-14. doi: 10.5056/jnm18139

Mossman, T. (1983). Rapid colorimetric assay for cellular growth and survival: application to proliferation and cytotoxicity assays. J. Immunol. Methods 65, 55-63. doi: 10.1016/0022-1759(83)90303-4

Ottoni, C. A., Maria, D. A., Gonçalves, P. J. R. O., de Araújo, W. L., and de Souza, A. O. (2019). Biogenic Aspergillus tubingensis silver nanoparticles' in vitro effects on human umbilical vein endothelial cells, normal human fibroblasts, HEPG2, and Galleria mellonella. Toxicol. Res. 8, 789-801. doi: 10. 1039/c9tx00091g

Puca, V., Traini, T., Guarnieri, S., Carradori, S., Sisto, F., Macchione, N., et al. (2019). The antibiofilm effect of a medical device containing TIAB on microorganisms associated with surgical site infection. Molecules 24:2280. doi: $10.3390 /$ molecules 24122280

Riaz, A. K. B., Nagy, A. M., Brown, R. P., Zhang, Q., Malghan, S. G., and Goering, P. L. (2017). Silver nanoparticles: significance of physicochemical properties and assay interference on the interpretation of in vitro cytotoxicity studies. Toxicol. In Vitro 38, 179-192. doi: 10.1016/j.tiv.2016.10.012

Rodrigues, A. G., Romano de Oliveira Gonçalves, P. J., Ottoni, C. A., de Cássia Ruiz, R., Morgano, M. A., de Araújo, W. L., et al. (2019). Functional textiles impregnated with biogenic silver nanoparticles from Bionectria ochroleuca and its antimicrobial activity. Biomed. Microdevices 21:56.

Ronci, M., Del Prete, S., Puca, V., Carradori, S., Carginale, V., Muraro, R., et al. (2019). Identification and characterization of the $\alpha-C A$ in the outer mem brane vesicles produced by Helicobacter pylori. J. Enzyme Inhib. Med. Chem. 34, 189-195. doi: 10.1080/14756366.2018.1539716

Saravanakumar, K., Chelliah, R., MubarakAli, D., Oh, D. H., Kathiresan, K., and Wang, M. H. (2019). Unveiling the potentials of biocompatible silver nanoparticles on human lung carcinoma A549 cells and Helicobacter pylori. Sci. Rep. 9:5787.

Savoldi, A., Carrara, E., Graham, D. Y., Conti, M., and Tacconelli, E. (2018). Prevalence of antibiotic resistance in Helicobacter pylori: a systematic review and meta-analysis in World Health Organization regions. Gastroenterology 155, 1372-1382. 
Scotti, L., Angelini, G., Gasbarri, C., and Bucciarelli, T. (2017). Uncoated negatively charged silver nanoparticles: speeding up the electrochemical synthesis. Mater. Res. Express 4:105001. doi: 10.1088/2053-1591/aa8c39

Shanmuganathan, R., Karuppusamy, I., Saravanan, M., Muthukumar, H., Ponnuchamy, K., Ramkumar, V. S., et al. (2019). Synthesis of silver nanoparticles and their biomedical applications - a comprehensive review. Curr. Pharm. Des. 25, 2650-2660. doi: 10.2174/1381612825666190708185506

Sharvil, S. P., Dhumal, R. S., Varghese, M. V., Paradkar, A. R., and Khanna, P. K. (2009). Synthesis and antibacterial studies of chloramphenicol loaded nanosilver against Salmonella typhi. Synth. React. Inorg. Met. Org. Nano Met. Chem. $39,65-72$.

Siddiqi, K. S., Husen, A., and Rao, R. A. K. (2018). A review on biosynthesis of silver nanoparticles and their biocidal properties. J. Nanobiotechnol. 16:14. doi: 10.1186/s12951-018-0334-5

Sisto, F., Brenciaglia, M. I., Scaltrito, M. M., and Dubini, F. (2000). Helicobacter pylori: ureA, cagA and VacA expression during conversion to the coccoid form. Int. J Antimicrob. Agents 15, 277-282. doi: 10.1016/s0924-8579(00)00188-6

Sisto, F., Scaltrito, M. M., Russello, G., Bonomi, A., and Dubini, F. (2009). Antimicrobial susceptibility testing of Helicobacter pylori determined by microdilution method using a new medium. Curr. Microbiol. 58, 559-563. doi: 10.1007/s00284-009-9368-0

Sondi, I., and Salopek-Sondi, B. (2004). Silver nanoparticles as antimicrobial agent: a case study on E. coli as a model for Gram-negative bacteria. J. Colloid Interface Sci. 275, 177-182. doi: 10.1016/j.jcis.2004.02.012

Stensberg, M. C., Wei, Q., McLamore, E. S., Porterfield, D. M., Wei, A., and Sepúlveda, M. S. (2011). Toxicological studies on silver nanoparticles: challenges and opportunities in assessment, monitoring and imaging. Nanomedicine 6, 879-898. doi: 10.2217/nnm.11.78

Suerbaum, S. (2000). Genetic variability within Helicobacter pylori. Int. J. Med. Microbiol. 290, 175-181. doi: 10.1016/s1438-4221(00)80087-9

Tang, S., and Zheng, J. (2018). Antibacterial activity of silver nanoparticles: structural effects. Adv. Healthc. Mater. 7:e1701503. doi: 10.1002/adhm. 201701503

Taylor, D. E., Eaton, M., Chang, N., and Salama, S. M. (1992). Construction of a Helicobacter pylori genome map and demonstration of diversity at the genome level. J. Bacteriol. 174, 6800-6806. doi: 10.1128/jb.174.21.6800-6806.1992

Ullah Khan, S., Saleh, T. A., Wahab, A., Khan, M. H. U., Khan, D., Ullah Khan, W., et al. (2018). Nanosilver: new ageless and versatile biomedical therapeutic scaffold. Int. J. Nanomed. 13, 733-762. doi: 10.2147/IJN S153167

Vimbela, G. V., Ngo, S. M., Fraze, C., Yang, L., and Stout, D. A. (2017). Antibacterial properties and toxicity from metallic nanomaterials. Int. J. Nanomed. 12, 3941-3965. doi: 10.2147/ijn.s134526

Yonezawa, H., Osaki, T., Hanawa, T., Kurata, S., Ochiai, K., and Kamiya, S. (2013). Impact of Helicobacter pylori biofilm formation on clarithromycin susceptibility and generation of resistance mutations. PLoS One 8:e73301. doi: 10.1371/ journal.pone.0073301

Yonezawa, H., Osaki, T., and Kamiya, S. (2015). Biofilm formation by Helicobacter pylori and its involvement for antibiotic resistance. Biomed. Res. Int. 2015:914791.

Yonezawa, H., Osaki, T., Kurata, S., Fukuda, M., Kawakami, H., Ochiai, K., et al. (2009). Outer membrane vesicles of Helicobacter pylori TK1402 are involved in biofilm formation. BMC Microbiol. 9:197. doi: 10.1186/1471-21809-197

Yonezawa, H., Osaki, T., Woo, T., Kurata, S., Zaman, C., Hojo, F., et al. (2011). Analysis of outer membrane vesicle protein involved in biofilm formation of Helicobacter pylori. Anaerobe 17, 388-390. doi: 10.1016/j.anaerobe.2011.03.020

Zengin, G., Menghini, L., Di Sotto, A., Mancinelli, R., Sisto, F., Carradori, S., et al. (2018). Chromatographic analyses, in vitro biological activities, and cytotoxicity of Cannabis sativa L. essential oil: a multidisciplinary study. Molecules 23:E3266.

Conflict of Interest: LS is the author of a pending European Patent (EP18181873.3)

The remaining authors declare that the research was conducted in the absence of any commercial or financial relationships that could be construed as a potential conflict of interest.

Copyright (c) 2020 Grande, Sisto, Puca, Carradori, Ronci, Aceto, Muraro, Mincione and Scotti. This is an open-access article distributed under the terms of the Creative Commons Attribution License (CC BY). The use, distribution or reproduction in other forums is permitted, provided the original author(s) and the copyright owner(s) are credited and that the original publication in this journal is cited, in accordance with accepted academic practice. No use, distribution or reproduction is permitted which does not comply with these terms. 